УДК 549.2:553.3/.4(571.151)

\title{
АКЦЕССОРНЫЕ НИОБИЙ-ТАНТАЛОВЫЕ МИНЕРАЛЫ АЛЕЙСКОГО ГРАНИТНОГО МАССИВА (СЗ РУДНОГО АЛТАЯ)
}

\author{
Новоселов Константин Леонидович, \\ nkonstantin1@rambler.ru \\ Национальный исследовательский Томский политехнический университет, \\ Россия, 634050, г. Томск, пр. Ленина, 30.
}

\begin{abstract}
Актуальность. Ниобий-танталовая акцессорная минерализация гранитоидов представляется важным дополнительным индикаторным признаком выявления потенциальной редкометальной рудоносности лейкогранитов - производных заключительной фазы становления полифразного Алейского гранитоидного массива $\left(D_{2-3}\right)$.

Цель исследования включает установление форм нахождения ниобия и тантала, а также сопутствующих им других редких элементов, изучение распространенности и возможностей использования их в качестве минералов-индикаторов условий формирования лейкогранитов.

Методы исследования включают традиционные минералого-петрографические, изучение видового состава акиессорных минералов в искусственных протолочках, начальный вес которых составлял 5...8 ке; аналитические исследования минералов выполнены в ИГМ CO PAH (г. Новосибирск) на электронном сканирующем микроскопе JSM-6510LV (Jeol Ltd) с энергодисперсионным спектрометром INCA Energy 350+ (аналитик мл. науч. сотр. М. В. Хлестов) и на рентгено-фрлюоресцентном микроскоnе (отделение геологии Инженерной школы природных ресурсов ТПУ, аналитик канд. геол.-минер. наук Рудмин М.А.).

Результаты. Установлены две формы нахождения ниобия и тантала в лейкограните Алейского массива: 1) структурная примесь в титаните, цирконе, апатите; 2) самостоятельные минералы ниобия и тантала - ильменорутил, колумбит. Концентрации ниобия обьчно резко доминируют над концентрациями тантала. Специфическая особенность химизма акцессорного колумбита - высокая железистость, и повышенные концентрации примесного скандия соответствует редкой разновидности - скандистому ферроколумбиту. Выделение минералов ниобия - ильменорутила и колумбита - происходило на постмагматическом этапе становления лейкогранитного интрузива в щелочную стадию автометасоматоза, причем ильменорутил по отношению к колумбиту является более ранним минералом.
\end{abstract}

\section{Ключевые слова:}

Рудный Алтай, гранитоиды, акцессорные минералы, ильменорутил, колумбит.

\section{Введение}

Алейский гранитоидный массив, площадью около 300 кв. км, расположен в пределах северной части Алейского поднятия, прорывает и метаморфизует терригенные отложения силурийско-нижнедевонской корбалихинской толщи. Массив имеет сложное полифазное строение с гомодромной последовательностью становления магматических тел - от габброидов ранней фазы до лейкогранитов заключительной четвертой, объединенных в составе среднепозднедевонского алейско-змеиногорского гранитоидного комплекса. Наибольшую часть площади массива занимают лейкограниты четвертой интрузивной фазы и по своим петрохимическим показателям отвечают гранитоидам А-типа [1].

Для лейкогранитов характерна несколько варьирующая структура от средне-крупнозернистой и слабо порфировидной до мелкозернистой и аплитовидной. Идиоморфные кристаллы плагиоклаза проявляют слабо выраженную зональность с постепенным переходом от олигоклаз-андезинового ядра к олигоклаз-альбитовой периферии. Калиевый полевой шпат представлен микроклином, который часто образует пертитовые каемки вокруг зерен плагиоклаза. Количественные соотношения микроклина и плагиоклаза непостоянны и варьируют от незначительного преобладания плагиоклаза до заметного доминирования микроклина. Темноцветные минералы представлены железистым биотитом, реже отмечается зеленая роговая обманка. Ведущая ассоциация акцессорных мине- ралов - титаномагнетит, ильменит, алланит, рутил, апатит, гематит, сфен, спессартин; в единичных зернах отмечаются ксенотим, циркон, монацит, турмалин, топаз, а также ильменорутил.

\section{Результаты исследования}

Ильменорутил и единичные зерна колумбита отмечены в электромагнитной фракции совместно с ильменитом, титаномагнетитом, рутилом, алланитом, спессартином. Подобная ассоциация акцессорных минералов отмечается в гранитоидах А-типа [2]. Зерна ильменорутила изометрической таблитчатой формы, размером 0,1..0,25 мм (рис. 1).

Исследование химического состава ильменорутила проведено в шести его зернах, каждое из которых анализировалось в 3-4 точках - в краевых и центральных частях. В химическом составе ильменорутила (табл. 1) содержания главных минералообразующих компонентов $\left(\mathrm{TiO}_{2}, \mathrm{FeO}, \mathrm{Nb}_{2} \mathrm{O}_{5}, \mathrm{Ta}_{2} \mathrm{O}_{5}\right)$ находятся в рамках его теоретического состава, приводимого в справочных руководствах $[3,4]$ и в работах предыдущих исследователей $[5,6]$. В качестве примесей постоянно присутствует ванадий, а в отдельных зернах эпизодически устанавливается кремний. Особенности химического состава минерала сводятся к следующему.

1. Содержания ниобия в ильменорутиле резко доминируют над танталом, коэффициент $\mathrm{Ta}_{2} \mathrm{O}_{5} / \mathrm{Nb}_{2} \mathrm{O}_{5}$ варьирует в широких пределах $(0,05 \ldots 0,31)$, в отдельных точках профиля зерна Та не устанавлива- 
ется, что подчеркивает его низкие концентрации и неравномерность распределения даже в пределах одного зерна.

2. Ильменорутил характеризуется обогащенностью титаном относительно количества ниобия и тантала $\left(\left(\mathrm{Nb}_{2} \mathrm{O}_{5}+\mathrm{Ta}_{2} \mathrm{O}_{5}\right) / \mathrm{TiO}_{2}=0,16 \ldots 0,32\right)$.

3. Ванадий в качестве структурной примеси $\left(\mathrm{V}^{5+} \leftrightarrow \mathrm{Nb}^{5+}\right)$ в ильменорутиле присутствует посто- янно $(0,34 \ldots 0,89 \%)$, в отдельных зернах содержание этого элемента повышается до 1,15\%. Повышенные содержания примеси $\mathrm{V}$ в ильменорутиле из гранитных пегматитов Среднего Урала отмечается многими исследователями [7, 8].

Кремний в качестве примеси фиксируется в отдельных точках зерен ильменорутила $(0,36 \ldots 0,88$ \%) и, видимо, является неструктурной примесью.

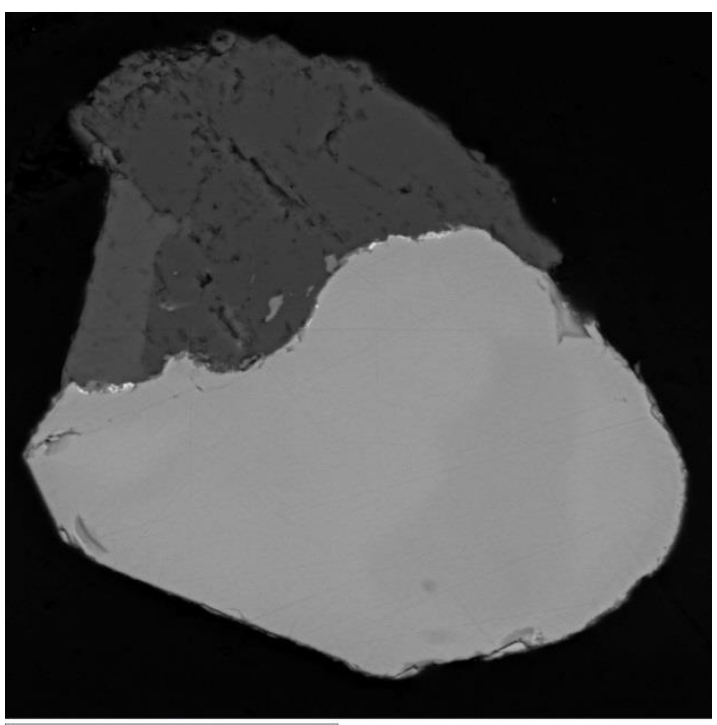

$60 \mu \mathrm{m}$

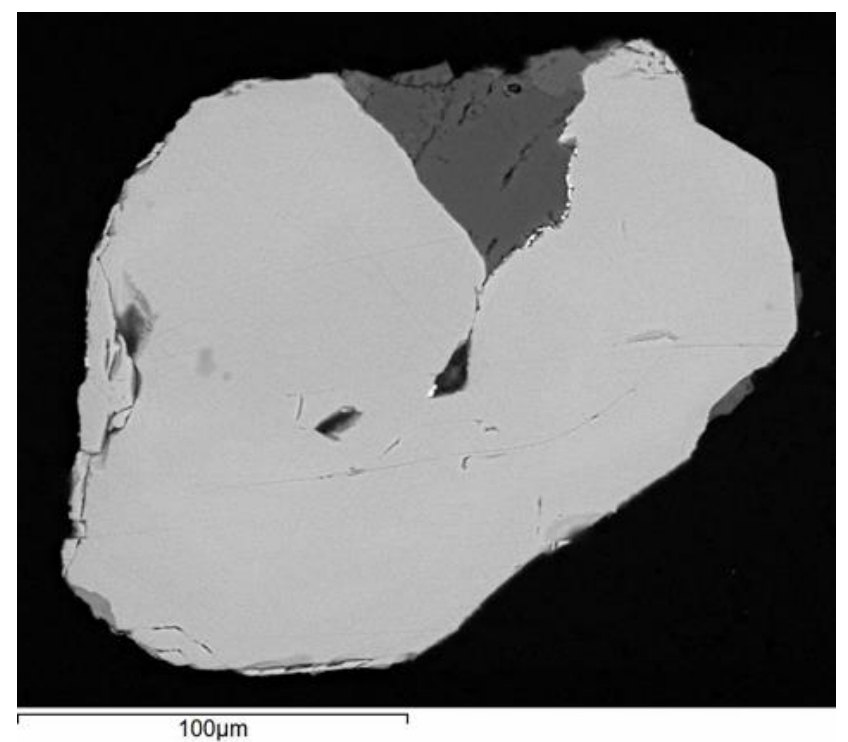

Рис. 1. Форма зерен ильменорутила. Здесь и на последующих рисунках изображение в обратно рассеянных электронах Fig. 1. Grain shape of ilmenorutile. In all figures - backscattered electron image

Таблица 1. Химический состав ильменорутила (мас. \%)

Table 1. Ilmenorutile chemical composition, wt. \%

\begin{tabular}{|c|c|c|c|c|c|c|c|c|c|}
\hline $\begin{array}{c}\text { № п.П } \\
\text { Ordinal number }\end{array}$ & $\begin{array}{l}\mathrm{FeO}_{\text {общ }} \\
\mathrm{FeO}_{\text {gen }}\end{array}$ & $\mathrm{TiO}_{2}$ & $\mathrm{Nb}_{2} \mathrm{O}_{5}$ & $\mathrm{Ta}_{2} \mathrm{O}_{5}$ & $\mathrm{~V}_{2} \mathrm{O}_{5}$ & $\mathrm{SiO}_{2}$ & $\begin{array}{c}\text { Cумма } \\
\text { Total }\end{array}$ & $\frac{\mathrm{Ta}_{2} \underline{\mathrm{O}}_{5}}{\mathrm{Nb}_{2} \mathrm{O}_{5}}$ & $\underline{\mathrm{Nb}_{2}} \underline{\mathrm{O}_{5}} \frac{\mathrm{O}_{5}}{\mathrm{TiO}_{2}} \underline{\mathrm{Ta}_{2}} \underline{\mathrm{O}_{5}}$ \\
\hline \multicolumn{10}{|c|}{ Зерно 1/Grain 1} \\
\hline 1 & 8,1 & 74,75 & 16,34 & 1,18 & 0,82 & $\begin{array}{lll}- & & \\
\end{array}$ & 101,2 & 0,07 & 0,23 \\
\hline 2 & 8,48 & 73,33 & 17,81 & 0,9 & 0,57 & - & 101,1 & 0,05 & 0,26 \\
\hline 3 & 8,61 & 71,29 & 17,54 & 2,92 & 0,51 & - & 100,9 & 0,17 & 0,28 \\
\hline 4 & 8,05 & 72,33 & 16,91 & 2,65 & 0,41 & 0,68 & 101,03 & 0,16 & 0,27 \\
\hline$\overline{\mathrm{X}}$ & 8,31 & 72,93 & 17,15 & 1,91 & 0,58 & - & 101,31 & 0,11 & 0,26 \\
\hline \multicolumn{10}{|c|}{ Зерно 2/Grain 2} \\
\hline 5 & 7,27 & 75,78 & 14,46 & 2,52 & 0,69 & 0,45 & 101,17 & 0,17 & 0,22 \\
\hline 6 & 9,01 & 69,04 & 19,71 & 2,47 & 0,43 & - & 100,66 & 0,13 & 0,32 \\
\hline 7 & 7,62 & 75,2 & 15,18 & 2,44 & 0,69 & 0,36 & 101,49 & 0,12 & 0,23 \\
\hline 8 & 8,94 & 70,46 & 16,88 & 4,69 & 0,34 & - & 101,31 & 0,28 & 0,31 \\
\hline$\overline{\mathrm{X}}$ & 8,21 & 72,62 & 16,56 & 3,03 & 0,54 & 0,41 & 101,16 & 0,175 & 0,27 \\
\hline \multicolumn{10}{|c|}{ Зерно 3/Grain 3} \\
\hline 9 & 7,81 & 73,69 & 15,32 & 2,42 & 0,65 & - & 99,89 & 0,16 & 0,24 \\
\hline 10 & 8,1 & 72,86 & 14,26 & 4,36 & 0,54 & - & 100,12 & 0,31 & 0,25 \\
\hline 11 & 8,89 & 72,34 & 18,71 & - & 0,59 & - & 100,53 & - & 0,26 \\
\hline$\overline{\mathrm{X}}$ & 8,27 & 72,96 & 16,09 & 3,39 & 0,59 & $\begin{array}{llll}- & & & \\
\end{array}$ & 100,18 & 0,235 & 0,25 \\
\hline \multicolumn{10}{|c|}{ Зерно 4/Grain 4} \\
\hline 12 & 9,25 & 68,87 & 19,03 & 3,19 & 0,56 & 0,79 & 101,69 & 0,17 & 0,3 \\
\hline 13 & 8,44 & 73,14 & 17,21 & 1,59 & 0,47 & 0,41 & 101,26 & 0,09 & 0,26 \\
\hline 14 & 8,39 & 73,33 & 17,17 & 1,67 & 0,41 & - & 100,97 & 0,1 & 0,26 \\
\hline$\overline{\mathrm{X}}$ & 8,69 & 71,78 & 17,80 & 2,15 & 0,48 & 0,60 & 101,31 & 0,12 & 0,27 \\
\hline \multicolumn{10}{|c|}{ Зерно 5/Grain 5} \\
\hline 15 & 8,14 & 72,33 & 17,12 & 2,48 & 0,56 & - & 100,63 & 0,14 & 0,27 \\
\hline 16 & 8,67 & 72,64 & 17,28 & 2,17 & 0,49 & - & 101,25 & 0,13 & 0,26 \\
\hline $\bar{X}$ & 8,41 & 72,49 & 17,2 & 2,33 & 0,53 & 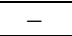 & 100,94 & 0,135 & 0,265 \\
\hline \multicolumn{10}{|c|}{ Зерно 6/Grain 6} \\
\hline 17 & 7,24 & 78,25 & 12,73 & - & 1,14 & 0,88 & 100,24 & - & 0,16 \\
\hline 18 & 6,97 & 78,32 & 12,86 & $\begin{array}{lll}- & & \\
-\end{array}$ & 0,89 & 0,75 & 99,79 & - & 0,16 \\
\hline 19 & 7,24 & 78,57 & 12,75 & 1,71 & 0,77 & - & 101,04 & 0,13 & 0,18 \\
\hline$\overline{\mathrm{X}}$ & 7,15 & 78,38 & 12,78 & - & 0,93 & 0,82 & 100,36 & - & 0,17 \\
\hline
\end{tabular}


Кристаллохимические формулы ильменорутила (номер формулы соответствует порядковому номеру анализа):

3. $\mathrm{Fe}_{0,315} \mathrm{Ti}_{2,347}\left(\mathrm{Nb}_{0,347} \mathrm{Ta}_{0,035} \mathrm{~V}_{0,015}\right)_{0,397} \mathrm{O}_{6}$

5. $\mathrm{Fe}_{0,262} \mathrm{Ti}_{2,456}\left(\mathrm{Nb}_{0,282} \mathrm{Ta}_{0,03} \mathrm{~V}_{0,02}\right)_{0,332} \mathrm{O}_{6}$

9. $\mathrm{Fe}_{0,285} \mathrm{Ti}_{2,42}\left(\mathrm{Nb}_{0,302} \mathrm{Ta}_{0,029} \mathrm{~V}_{0,019}\right)_{0,35} \mathrm{O}_{6}$

11. $\mathrm{Fe}_{0,322} \mathrm{Ti}_{2,359}\left(\mathrm{Nb}_{0,367} \mathrm{~V}_{0,017}\right)_{0,384} \mathrm{O}_{6}$

17. $\mathrm{Fe}_{0,262} \mathrm{Ti}_{2,553}\left(\mathrm{Nb}_{0,22} \mathrm{~V}_{0,033}\right)_{0,253} \mathrm{O}_{6}$

В формулах ильменорутила несколько завышен коэффициент железа вследствие использования в

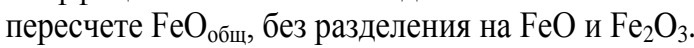

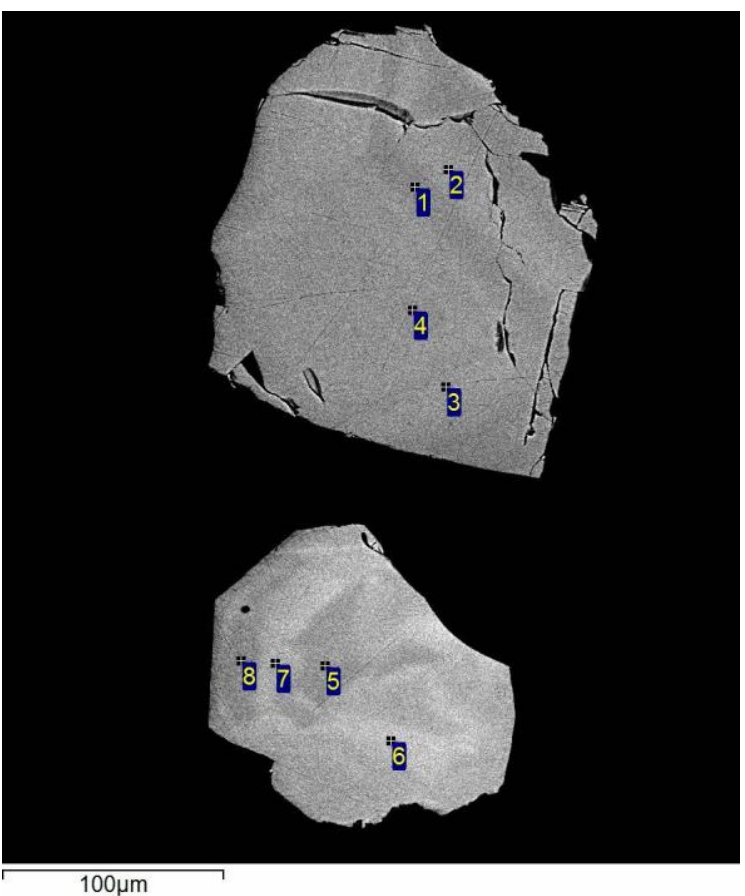

Рис. 2. Зональные зерна ильменорутила. Номера точек на рисунке соответствуют номерам анализов в табл. 2

Fig. 2. Zonal grains of ilmenorutile. The numbers of points in the figure correspond to the numbers of analyzes in table 2

На отдельных кристаллах ильменорутила проявляется зональное строение в виде чередования «свет- лых» и «темных» полос с несколько расплывчатыми границами (рис. 2).

Кристаллохимические формулы:

«Темные» зоны

1. $\mathrm{Fe}_{0,256} \mathrm{Ti}_{2,472}\left(\mathrm{Nb}_{0,282} \mathrm{~V}_{0,022} \mathrm{Ta}_{0,017}\right)_{0,321} \mathrm{O}_{6}$

4. $\mathrm{Fe}_{0,273}\left(\mathrm{Ti}_{2,471} \mathrm{Al}_{0,018}\right)_{2,489}\left(\mathrm{Nb}_{0,28} \mathrm{Ta}_{0,023}\right)_{0,303} \mathrm{O}_{6}$

5. $\mathrm{Fe}_{0,314} \mathrm{Ti}_{2,376}\left(\mathrm{Nb}_{0,343} \mathrm{Ta}_{0,012} \mathrm{~V}_{0,019}\right)_{0,374} \mathrm{O}_{6}$

8. $\mathrm{Fe}_{0,3} \mathrm{Ti}_{2,406}\left(\mathrm{Nb}_{0,321} \mathrm{Ta}_{0,019} \mathrm{~V}_{0,015}\right)_{0,355} \mathrm{O}_{6}$

«Светлые» зоны

2. $\mathrm{Fe}_{0,266} \mathrm{Ti}_{2,476}\left(\mathrm{Nb}_{0,268} \mathrm{Ta}_{0,028} \mathrm{~V}_{0,016}\right)_{0,312} \mathrm{O}_{6}$

3. $\mathrm{Fe}_{0,284} \mathrm{Ti}_{2,453}\left(\mathrm{Nb}_{0,279} \mathrm{Ta}_{0,034} \mathrm{~V}_{0,011}\right)_{0,324} \mathrm{O}_{6}$

6. $\mathrm{Fe}_{0,314} \mathrm{Ti}_{2,364}\left(\mathrm{Nb}_{0,324} \mathrm{Ta}_{0,046} \mathrm{~V}_{0,014}\right)_{0,384} \mathrm{O}_{6}$

7. $\mathrm{Fe}_{0,304} \mathrm{Ti}_{2,378}\left(\mathrm{Nb}_{0,33} \mathrm{Ta}_{0,03} \mathrm{~V}_{0,016}\right)_{0,376} \mathrm{O}_{6}$

Химический состав «светлых» и «темных» $30 н$ ильменорутила несколько отличается концентрациями минералообразующих компонентов: в «светлых» зонах вдвое выше содержание тантала, также несколько повышена кремнеземистость, снижена титанистость (табл. 2).

По краю зерен ильменорутила, а также в их трещинках и пустотках часто наблюдаются включения агрегатов зерен альбита, кварца, ниобий-содержащего титани$\mathrm{Ta}-\mathrm{Ca}_{1,159}\left(\mathrm{Ti}_{0,793} \mathrm{Nb}_{0,179} \mathrm{Fe}_{0,066}\right)_{1,038}\left[\left(\mathrm{Si}_{0,729} \mathrm{Al}_{0,189}\right)_{0,918} \mathrm{O}_{4}\right] \mathrm{O}$.

В единичном зерне ильменорутила в пустотке и по его периферии отмечено два кристалла ксенотима (рис. 3), редкоземельного, уран-ториевого по составу. Кристаллохимическая формула ксенотима: $\left(\mathrm{Y}_{0,662} \mathrm{Dy}_{0,061} \mathrm{Yb}_{0,043} \mathrm{Er}_{0,035} \mathrm{Gd}_{0,033} \mathrm{Ca}_{0,03} \mathrm{Ti}_{0,024} \mathrm{U}_{0,014} \mathrm{Th}_{0,01}\right)_{0,912}$ $\left(\mathrm{P}_{0,979} \mathrm{Si}_{0,06}\right)_{1,039} \mathrm{O}_{4}$.

Колумбит, как и ниобиевый титанит, образует вростки кристаллов, приуроченных к трещинкам и пустоткам зерна ильменорутила (рис. 4). Подобные включения зерен колумбита в ильменорутиле отмечаются в работах ряда исследователей редкометальных гранитоидов и пегматитов Южного Урала [9-13]. Один кристалл колумбита, размером около 14 мкм, имеет идиоморфную, близкую к прямоугольной, форму с отходящими «ответвлениями» в матрицу ильменорутила, второе зерно, размером около 20 мкм, с неровными извилистыми краями вместе с титанитом выполняет пустотку в ильменорутиле (рис. 4).

Таблица 2. Химический состав зональных кристаллов ильменорутила (мас. \%)

Table 2. Chemical composition of zonal crystals of ilmenorutile, wt. \%

\begin{tabular}{|c|c|c|c|c|c|c|c|c|c|}
\hline $\begin{array}{c}\text { № } 30 \mathrm{H} \\
\text { Zone number }\end{array}$ & $\begin{array}{l}\mathrm{FeO}_{\text {обш }} \\
\mathrm{FeO}_{\text {gen }}\end{array}$ & $\mathrm{TiO}_{2}$ & $\mathrm{Nb}_{2} \mathrm{O}_{5}$ & $\mathrm{Ta}_{2} \mathrm{O}_{5}$ & $\mathrm{~V}_{2} \mathrm{O}_{5}$ & $\mathrm{SiO}_{2}$ & $\begin{array}{c}\text { Сумма } \\
\text { Total }\end{array}$ & $\frac{\mathrm{Ta}_{2} \underline{\mathrm{O}}_{5}}{\mathrm{Nb}_{2} \mathrm{O}_{5}}$ & $\underline{\mathrm{Nb}_{2}} \frac{\mathrm{O}_{5}}{\mathrm{~T}_{1}+\mathrm{Ta}_{2}} \underline{\mathrm{O}}_{5}$ \\
\hline \multicolumn{10}{|c|}{ «темные» зоны/«dark» zones } \\
\hline 1 & 7,14 & 76,45 & 14,49 & 1,42 & 0,76 & - & 100,26 & 0,098 & 0,21 \\
\hline 4 & 7,56 & 76,23 & 14,38 & 1,98 & - & 0,34 & 100,49 & 0,138 & 0,21 \\
\hline 5 & 8,65 & 72,84 & 17,52 & 1,0 & 0,6 & 0,32 & 100,93 & 0,057 & 0,25 \\
\hline 8 & 8,29 & 73,89 & 16,41 & 1,61 & 0,51 & - & 100,71 & 0,098 & 0,24 \\
\hline$\overline{\mathrm{X}}$ & 7,91 & 74,85 & 15,7 & 1,5 & 0,62 & 0,33 & 100,60 & 0,096 & 0,23 \\
\hline \multicolumn{10}{|c|}{ «светлые» зоны/«light-coloured» zones } \\
\hline 2 & 7,33 & 75,95 & 13,69 & 2,39 & 0,57 & 0,63 & 100,56 & 0,175 & 0,21 \\
\hline 6 & 8,52 & 71,39 & 16,28 & 3,82 & 0,47 & 0,88 & 101,36 & 0,235 & 0,28 \\
\hline 7 & 8,36 & 72,63 & 16,75 & 2,95 & 0,57 & 0,64 & 101,9 & 0,176 & 0,27 \\
\hline 3 & 7,9 & 75,75 & 14,31 & 2,91 & 0,4 & - & 101,27 & 0,203 & 0,23 \\
\hline$\overline{\mathrm{X}}$ & 8,0 & 73,93 & 15,26 & 3,02 & 0,5 & 0,72 & 101,27 & 0,198 & 0,25 \\
\hline
\end{tabular}

Примечание. Номер в таблице соответствует точкам анализа зон ильменорутила, обозначенным на рис. 2. Note. The number in the table corresponds to the points of analysis of the ilmenorutile zones indicated in Fig. 2. 


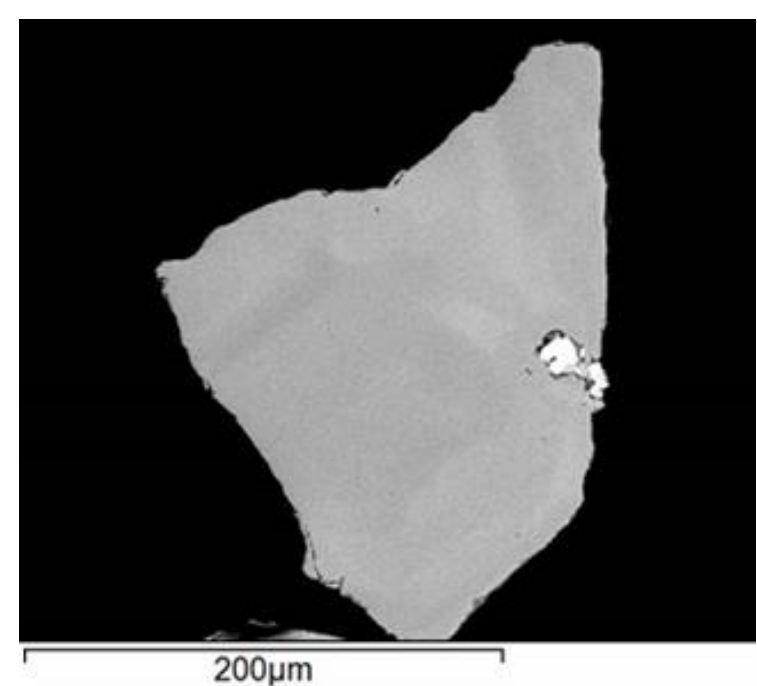

Рис. 3. Включения кристаллов ксенотима (белое) в зерне ильменорутила

Fig. 3. Inclusions of xenotime crystals (white) in ilmenorutile grain

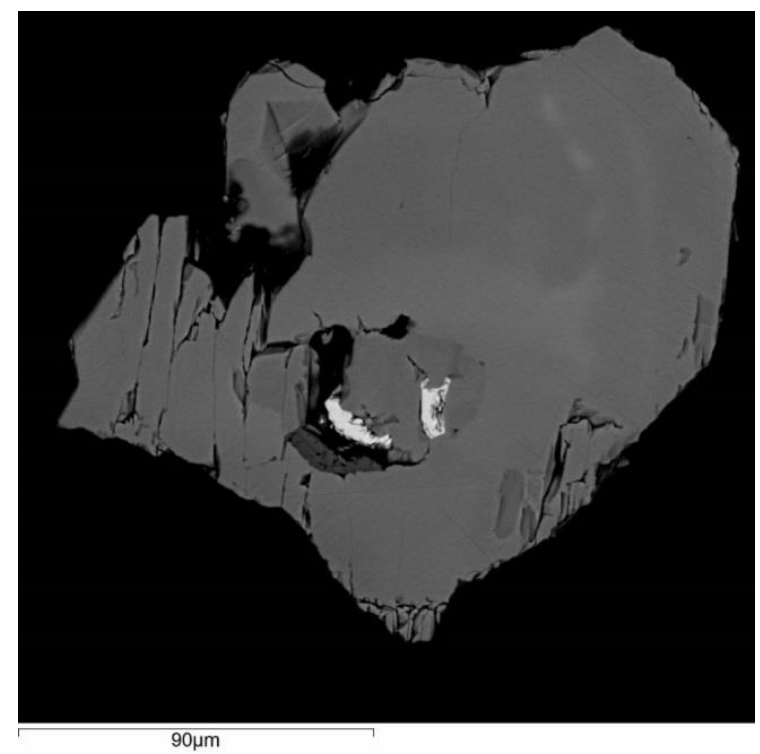

Pис. 4. Включения зерен колумбита (белое) в пустотах и трещинах зерна ильменорутила

Fig. 4. Inclusions of columbite grains (white) in voids and fissures of ilmenorutile grain

В химическом составе колумбита (табл. 3) ниобий резко доминирует над танталом, коэффициент танталниобиевого отношения варьирует $(0,012 \ldots 0,014)$ при неизменно низком содержании тантала $(0,81 \ldots 0,84 \%)$. Преобладание $\mathrm{Nb}$ над Та типично для акцессорных колумбитов гранитоидов [14-17]. Для колумбита характерны железистость $(17,64 \ldots 19,16 \%)$ и весьма низкая марганцовистость $(0,19 \ldots 0,3 \%)$, коэффициент отношения $\mathrm{Mn} /(\mathrm{Mn}+\mathrm{Fe})$ не превышает $0,01 \ldots 0,02$. Постоянно присутствует и в повышенных количествах $(6,14 \ldots 10,01 \%)$ примесь титана, изоморфно замещающего ниобий (по схеме $\mathrm{Ti}^{4+} \leftrightarrow \mathrm{Nb}^{5+}$ ). Обращает внимание постоянное присутствие в повышенных количествах скандия $(1,03 \ldots 1,84 \%)$, образующего структурную примесь по схеме $\mathrm{Sc}^{3+} \leftrightarrow \mathrm{Fe}^{2+}[18]$. Дру- гие примесные элементы ( $\mathrm{Al}, \mathrm{Si}, \mathrm{Ca})$ по их концентрации в составе колумбита не значительны.

Таким образом, по составу и степени насыщенности примесными элементами изучаемый минерал отвечает редкой разновидности - скандистому ферроколумбиту [3], и его кристаллохимические формулы следующие:

1. $\left(\mathrm{Fe}_{0,884} \mathrm{Sc}_{0,050} \mathrm{Ca}_{0,021} \mathrm{Mn}_{0,009}\right)_{0,964}\left(\mathrm{Nb}_{1,789} \mathrm{Ti}_{0,255} \mathrm{Ta}_{0,012}\right)_{2,056} \mathrm{O}_{6}$

2. $\left(\mathrm{Fe}_{0,878} \mathrm{Sc}_{0,071} \mathrm{Ca}_{0,024} \mathrm{Mn}_{0,015}\right)_{0,988}\left(\mathrm{Nb}_{1,654} \mathrm{Ti}_{0,403} \mathrm{Ta}_{0,013}\right)_{2,07} \mathrm{O}_{6}$

3. $\left(\mathrm{Fe}_{0,871} \mathrm{Sc}_{0,058} \mathrm{Mn}_{0,009} \mathrm{Ca}_{0,008}\right)_{0,946}\left(\mathrm{Nb}_{1,685} \mathrm{Ti}_{0,392} \mathrm{Ta}_{0,012}\right)_{2,089} \mathrm{O}_{6}$

4. $\left(\mathrm{Fe}_{0,904} \mathrm{Sc}_{0,092} \mathrm{Mn}_{0,013}\right)_{1,009}\left(\mathrm{Nb}_{1,617} \mathrm{Ti}_{0,434} \mathrm{Ta}_{0,013}\right)_{2,064} \mathrm{O}_{6}$

Кроме самостоятельных минеральных форм ниобий в качестве изоморфной примеси установлен в цирконе $(2,53 \ldots 2,83 \%)$, рутиле $(5,05 \ldots 9,64 \%)$, ильмените $(0,03 \ldots 0,7 \%)$, тантал концентрируется в апатите $(0,48 \ldots 0,51 \%)$, ильмените $(0,01 \ldots 0,07 \%)$ [19].

\section{Обсуждение результатов исследования и выводы}

Изучаемые лейкограниты представляют собой производные четвертой, заключительной фазы становления гранитоидов алейско-змеиногорского комплекса $\left(\mathrm{D}_{2-3}\right)$. B составе акцессорных минералов лейкогранитов наибольшие весовые количества образуют минералы железа и титана - титаномагнетит, гематит, ильменит, рутил, титанит, а также присутствуют минералы редких и редкоземельных металлов - ильменорутил, колумбит, ксенотим.

Видовой состав раннемагматических акцессорных минералов - циркон, апатит, ильменит, рутил, титаномагнетит, титанит, а также содержание в них примесных редких элементов позволяет сделать вывод о присутствии в расплаве рудных, редкометальных, редкоземельных элементов - Ti, $\mathrm{Fe}, \mathrm{V}, \mathrm{Zr}, \mathrm{Nb}, \mathrm{Ta}$, а также U, Th. На магматическом этапе $\mathrm{Nb}^{5+}$ и $\mathrm{Ta}^{5+}$ образовывали изоморфную примесь в цирконе, апатите, титаните, ильмените, магнетите; не вошедшие в решётки ранних акцессорных минералов $\mathrm{Nb}$ и $\mathrm{Ta}$ накапливались в остаточном расплаве. В постмагматическую стадию формирования гранитоидов проявился щелочной автометасоматоз, который хорошо подтверждается использованием отношений петрогенных оксидов [20]. Согласно рассчитанным отношениям, гранитоиды разделились на две группы: 1 лейкограниты, «незатронутые» процессом автометасоматоза, и 2 - лейкограниты, подвергшиеся автометасоматозу, который проявился в их альбитизации и калишпатизации. Акцессорные минералы ниобия ильменорутил и колумбит, присутствуют лишь в метасоматически измененных лейкогранитах.

Формы зерен ильменорутила, близкие к кристаллогранным, распространенность зональных индивидов, постоянно присутствующая примесь ванадия указывают на его более раннюю стадию постмагматической кристаллизации и обогащенность остаточного метасоматического раствора редкими металлами - $\mathrm{Nb}, \mathrm{Ta}, \mathrm{V}$, Ti и др. Разброс величин ниобий-танталового отношения в ильменорутиле, присутствие зональных его индивидов свидетельствует о меняющемся режиме щелочности - кислотности метасоматизирующего раствора. Повышенная щелочность остаточного раствора обусловила доминирование $\mathrm{Nb}$ над Та. 
Таблица 3. Химический состав колумбита (мас. \%)

Table 3. Columbite chemical composition, wt. \%

\begin{tabular}{|c|c|c|c|c|c|c|c|c|c|c|c|}
\hline $\begin{array}{c}\text { № П.П } \\
\text { Ordinal number }\end{array}$ & $\begin{array}{l}\mathrm{FeO}_{\text {общ }} \\
\mathrm{FeO}_{\text {gen }}\end{array}$ & $\mathrm{MnO}$ & $\mathrm{Nb}_{2} \mathrm{O}_{5}$ & $\mathrm{Ta}_{2} \mathrm{O}_{5}$ & $\mathrm{TiO}_{2}$ & $\mathrm{Sc}_{2} \mathrm{O}_{3}$ & $\mathrm{CaO}$ & $\mathrm{Al}_{2} \mathrm{O}_{3}$ & $\mathrm{SiO}_{2}$ & $\begin{array}{l}\text { Сумма } \\
\text { Total }\end{array}$ & $\frac{\mathrm{Ta}_{2}}{\mathrm{Nb}_{2}} \frac{\mathrm{O}_{5}}{\mathrm{O}_{5}}$ \\
\hline 1 & 19,16 & 0,19 & 71,77 & 0,83 & 6,14 & 1,03 & 0,35 & - & 0,36 & 99,83 & 0,012 \\
\hline 2 & 17,64 & 0,3 & 61,47 & 0,82 & 9,01 & 1,37 & 0,38 & 0,51 & 0,56 & 92,04 & 0,013 \\
\hline 3 & 18,94 & 0,19 & 67,78 & 0,81 & 9,47 & 1,2 & 0,14 & 0,28 & 0,28 & 99,09 & 0,012 \\
\hline 4 & 18,78 & 0,26 & 62,1 & 0,84 & 10,01 & 1,84 & - & 0,32 & 0,47 & 94,62 & 0,014 \\
\hline
\end{tabular}

Скандистый ферроколумбит, кристаллы которого выполняют трещинки и пустотки в зернах ильменорутила, выделился на заключительном этапе щелочного автометасоматоза в условиях высокой активности $\mathrm{Sc}, \mathrm{Ti}, \mathrm{Fe}, \mathrm{Ca}$, редких и редкоземельных элементов, а также урана и тория.

\section{СПИСОК ЛИТЕРАТУРЫ}

1. Туркин Ю.А., Новоселов К.Л. Петролого-геохимические особенности девонских гранитоидов северо-западной части Рудного Алтая // Известия Томского политехнического университета. - 2012. - Т. 321. - № 1. - С. 5-15.

2. Petrogenesis and geodynamic implications of Ediacaran highly fractionated A-type granitoids in the north Arabian-Nubian Shield (Egypt): constraints from whole-rock geochemistry and $\mathrm{Sr}-\mathrm{Nd}$ isotopes / M. Sami, Th. Ntaflos, E.S. Farahat, H.A. Mohamed, Ch. Hauzenberger, A.F. Ahmed // Lithos. - 2018. - V. 304-307. Р. 329-346.

3. Солодов Н.А., Семенов Е.И., Бурков В.В. Геологический справочник по тяжелым литофильным редким металлам / под ред. Н.П. Лаверова. - М.: Недра, 1987. - 438 с.

4. Минералы (справочник). Т. ІІ. Вып. 2. Простые окислы / под ред. Ф.В. Чухрова, Э.М. Бонштедт-Куплетской. - М.: Наука, 1965. $-342 \mathrm{c}$.

5. Niobian rutile from the McGuire granitic pegmatite, Park County, Colorado: solid solution, exsolution, and oxidation / P. Černý, R. Chapman, W.B. Simmons, L.E. Chackowsky // American Mineralogist. - 1999. - V. 84. - P. 754-763.

6. Subsolidus behavior of niobian rutile from Věžná, Czech Republic: a model for exsolutions in phases with $\mathrm{Fe} 2+>\mathrm{Fe} 3+/ \mathrm{P}$. Cerný, M. Novák, R. Chapman, M. Masau // Journal of the Czech Geological Society. - 2000. - № 45/1-2. - P. 21-35.

7. Гракова О.В. Акцессорный ильменорутил из алмазсодержащих среднедевонских пород Южного Тимана // Вестник. 2011, октябрь. - № 10. - С. 11-13.

8. Редкометалльная минерализация гранитных пегматитов Режевского района на Среднем Урале / В.И. Попова, В.А. Губин, Е.И. Чурин, В.А. Котляров, В.В. Хиллер // Записки Российского минералогического общества. - 2013. - Ч. CXLII. № 1. - С. 23-38.

9. Ферроколумбит-ильменорутиловые графические срастания из гранитных пегматитов Миассово-Таткульского жильного поля Ильменских гор / В.И. Попова, А.А. Леванов, В.А. Попов, Л.Н. Поспелова // Уральское отделение РАН, Уральский минералогический сборник. - 2001. - № 11. - С. 14-21.

10. Савельева В.Б., Базарова Е.П., Карманов Н.С. Акцессорные минералы Приморского комплекса гранитов рапакиви (Западное Прибайкалье) // Записки Российского минералогического общества. - 2011. - Ч. СХXXX. - № 2. - С. 38-58.
Таким образом, в постмагматическую стадию формирования лейкогранитов алейско-змеиногорского комплекса проявился щелочной автометазоматоз, в результате которого образовались ильменорутил, скандистый ферроколумбит, уран-ториевый редкоземельный ксенотим.

11. Макеев А.Б., Борисовский С.Е. Типоморфизм и источники титановых и ниобиевых минералов проявления Ичетью, Средний Тиман // Известия ВУЗов. Геология и разведка. 2013. - № 2. - C. 30-37.

12. Ерохин Ю.В., Захаров А.В., Хиллер В.В. Ниобиевая минерализация гранитных пегматитов Липовского жильного поля (Средний Урал) // Труды Института геологии и геохимии Уральского отделения Российской Академии наук. - 2014. Вып. 161. - С. 253-256.

13. Titaniferous heavy mineral aggregates as a tool in exploration for pegmatitic and aplitic rare-metal deposits (SE Germany) / H.G. Dill, B. Weber, F. Melcher, W. Wiesner, A. Müller // Ore Geology Reviews. - 2014. - V. 57. - P. 29-52.

14. London D. Ore-forming processes within granitic pegmatites // Ore Geology Reviews. - 2018. - V. 101. - P. 343-383.

15. Mineralogical and chemical evolution of tantalum-(niobium-tin) mineralisation in pegmatites and granites. P. 2: Worldwide examples (excluding Africa) and an overview of global metallogenetic patterns / F. Melcher, T. Graupner, H.-E. Gäbler, M. Sitnikova, T. Oberthür, A. Gerdes, E. Badanina, T. Chudy // Ore Geology Reviews. - 2017. - V. 89. - P. 946-987.

16. Petrogenesis of syn-orogenic rare metal pegmatites in the Chinese Altai: evidences from geology, mineralogy, zircon U-Pb age and Hf isotope / Zheng-Hang Lv, Hui Zhang, Yong Tang, Yun-Long Liu, Xin Zhang // Ore Geology Reviews. - 2018. - V. 95. P. 161-181.

17. Mineralogical and geochemical characteristics of the Miaoya REE prospect, Qinling Orogenic Belt, China: insights from Sr-Nd-C-O isotopes and LA-ICP-MS mineral chemistry / D. Zhang, Y. Liu, J. Pan, T. Dai, R.C. Bayless // Ore Geology Reviews. - 2019. V. 210. DOI: https://doi.org/10.1016/j.oregeorev.2019.05.018

18. Макаров Е.С. Изоморфизм атомов в кристаллах. - М.: Атомиздат, 1973. $-288 \mathrm{c}$.

19. Novoselov K.L., Gavrilova K.A. Typomorphic characteristic features of accessory ilmenite in granitoids of the polyphase Aleisk-Zmeinogorsk complex (N-W Rudny Altai area) // MATEC Web of Conferences. - 2016. - V. 85: Chemistry and Chemical Technology in XXI Century (ССТ 2016). - 4 p.

20. Кудрин В.С., Кудрина М.А., Шуряга Т.Н. Редкометальные метасоматические образования, связанные с субщелочными гранитоидами // Геология месторождений редких элементов. М.: Недра, 1965. - Вып. 25. - 147 с.

Поступила 18.06.2019 г.

\section{Информация об аворах}

Новоселов К.Л., кандидат геолого-минералогических наук, доцент отделения геологии Инженерной школы природных ресурсов, Национальный исследовательский Томский политехнический университет. 
UDC 549.2:553.3/.4(571.151)

\title{
ACCESSORY NIOBIUM-TANTALUM MINERALS OF THE ALEISK GRANITE MASSIF (N-W RUDNY ALTAY AREA)
}

\author{
Konstantin L. Novoselov, \\ nkonstantin1@rambler.ru \\ National Research Tomsk Polytechnic University, \\ 30, Lenin avenue, Tomsk, 634050, Russia.
}

Relevance of the research. Accessory niobioum-tantalum mineralization of granitoids is an important additional feature at detecting potential rare-metal ore content of leucogranites, which are the derivatives of the final stage of polyphase Aleisk granitoid massif $\left(D_{2-3}\right)$ formation.

The aim of the research is to discover the forms of niobium and tantalum occurrence as well as the other corresponding rare elements. It includes investigation of their spread and possibilities for their usage as minerals-indicators for conditions of leucogranite formation.

Methods: traditional mineralogical and petrographic studies of accessory mineral composition in artificial crushed samples, the initial weight of which is about 5-8 kg. Analytical investigation of minerals is performed in the Institute of Geology and Mineralogy (SB RAS, Novosibirsk), using an electronic scanning microscope JSM-6510LV (Jeol Ltd) with an energy dispersive spectrometer INCA Energy 350+ (the analyst M.V. Khlestov, junior research scientist). X-ray fluorescent microscope is used (the Division for Geology, School of Earth Science and Engineering, TPU, the analyst M.A. Rudmin, Cand. Sc.).

Results. Two forms of niobium and tantalum occurrence are discovered in the leucogranite of the Aleisk massif: 1) structural impurity in titanite, zircon, and apatite; 2) individual minerals of niobium and tantalum - ilmenorutile and columbite. Usually niobium concentrations dominate distinctly over tantalum. The striking feature of chemistry of accessory columbite is its high ferruginosity, and enhanced concentrations of impurity scandium correspond to a rare type - scandium ferrocolumbite. Crystallization of niobium minerals (ilmenorutile and columbite) occurred at the post-magmatic period of leucogranite intrusive formation during the alkali stage of autometasomatism. Notably, ilmenorutile is an older mineral in regard to columbite.

\section{Key words:}

Rudny Altay, granitoids, accessory minerals, ilmenorutile, columbite.

\section{References}

1. Turkin Yu.A., Novoselov K.L. Petrological and geochemical features of Devonian granitoids in north-west part of Rudny Altai. Bulletin of the Tomsk Polytechnic University, 2012, vol. 321, no. 1, pp. 5-15. In Rus.

2. Sami M., Ntaflos Th., Farahat E.S., Mohamed H.A., Hauzenberger Ch., Ahmed A.F. Petrogenesis and geodynamic implications of Ediacaran highly fractionated A-type granitoids in the north Arabian-Nubian Shield (Egypt): Constraints from wholerock geochemistry and Sr-Nd isotopes. Lithos, 2018, vol. 304-307, pp. 329-346.

3. Solodov N.A., Semenov E.I., Burkov V.V. Geologicheskiy spravochnik po tyazhelym litofilnym redkim metallam [Geological reference book on heavy lithophile rare metals]. Ed. by N.P. Laverov. Moscow, Nedra Publ., 1987. 438 p.

4. Mineraly. Spravochnik [Minerals. Reference book]. Vol. II. Iss. 2 Prostye okisly [Simple oxides]. Eds. F.V. Chukhrov, E.M Bonshtedt-Kupletskaya. Moscow, Nauka Publ., 1965. 342 p.

5. Černý P., Chapman R., Simmons W.B., Chackowsky L.E. Niobian rutile from the McGuire granitic pegmatite, Park County, Colorado: Solid solution, exsolution, and oxidation. American Mineralogist, 1999, vol. 84, pp. 754-763.

6. Černý P., Novák M., Chapman R., Masau M. Subsolidus behavior of niobian rutile from Věžná, Czech Republic: a model for exsolutions in phases with $\mathrm{Fe}^{2+}>\mathrm{Fe}^{3+}$. Journal of the Czech Geological Society, 2000, no. 45/1-2, pp. 21-35.

7. Grakova O.V. Accessory ilmenorutile of diamondiferous middledevonian deposits of South Timan. Vestnik, October, 2011, no. 10, pp. 11-13. In Rus.

8. Popova V.I., Gubin V.A., Churin E.I., Kotlyarov V.A., Hiller V.V. Rare metal mineralization in granite pegmatites of Rezhevsky area at the Middle Urals. Proceedings of the Russian Mineralogical Society, 2013, Pt. CXLII, no. 1, pp. 23-38. In Rus.

9. Popova V.I., Levanov A.A., Popov V.A., Pospelova L.N Ferrocolumbite-ilmenorutile graphic intergrowth from the TatkulMiassovo field granite pegmatite, Ilmen Mountains. Uralskiy mineralogicheskiy sbornic, 2001, no. 11, pp. 14-21. In Rus.
10. Saveleva V.B., Bazarova E.P., Karmanov N.S. Accessory minerals of the Primorsky rapakivi granite complex (The West Baikal region). Proceedings of the Russian Mineralogical Society, 2011, Pt. CXXXX, no. 2, pp. 38-58. In Rus.

11. Makeev A.B., Borisovskiy S.E. Tipomorfizm i istochniki titanovykh i niobievykh mineralov proyavleniya Ichetyu, Sredniy Timan [Typomorphism and sources of titanium and niobic minerals of Ichetue deposit, Middle Timan]. Izvestiya vuzov. Geologiya i razvedka, 2013, no. 2, pp. 30-37.

12. Erokhin Yu.V., Zakharov A.V., Hiller V.V. Niobievaya mineralizatsiya granitnykh pegmatitov Lipovskogo zhilnogo polya (Sredniy Ural) [Niobic mineralization of Lipovsky vien field granitic pegmatites (Middle Ural)]. Trudy Instituta geologii $i$ geokhimii Uralskogo otdeleniya Rossiyskoy Akademii nauk, 2014, Iss. 161 , pp. 253-256.

13. Dill H.G., Weber B., Melcher F., Wiesner W., Müller A. Titaniferous heavy mineral aggregates as a tool in exploration for pegmatitic and aplitic rare-metal deposits (SE Germany). Ore Geology Reviews, 2014, vol. 57, pp. 29-52.

14. London D. Ore-forming processes within granitic pegmatites. Ore Geology Reviews, 2018, vol. 101, pp. 343-383.

15. Melcher F., Graupner T., Gäbler H.-E., Sitnikova M., Oberthür T., Gerdes A., Badanina E., Chudy T. Mineralogical and chemical evolution of tantalum-(niobium-tin) mineralisation in pegmatites and granites. P. 2: Worldwide examples (excluding Africa) and an overview of global metallogenetic patterns. Ore Geology Reviews, 2017, vol. 89, pp. 946-987.

16. Zheng-Hang Lv, Hui Zhang, Yong Tang, Yun-Long Liu, Xin Zhang. Petrogenesis of syn-orogenic rare metal pegmatites in the Chinese Altai: Evidences from geology, mineralogy, zircon $\mathrm{U}-\mathrm{Pb}$ age and $\mathrm{Hf}$ isotope. Ore Geology Reviews, 2018, vol. 95, pp. 161-181.

17. Zhang D., Liu Y., Pan J., Dai T., Bayless R.C. Mineralogical and geochemical characteristics of the Miaoya REE prospect, Qinling Orogenic Belt, China: insights from Sr-Nd-C-O isotopes and LAICP-MS mineral chemistry. Ore Geology Reviews, 2019, vol. 210. DOI: https://doi.org/10.1016/j.oregeorev.2019.05.018

18. Makarov E.S. Izomorfizm atomov v kristallakh [Isomorphism of atoms in crystals]. Moscow, Atomizdat Publ., 1973. 288 p. 
19. Novoselov K.L., Gavrilova K.A. Typomorphic characteristic features of accessory ilmenite in granitoids of the polyphase Aleisk-Zmeinogorsk complex (N-W Rudny Altai area). MATEC Web of Conferences, 2016, vol. 85: Chemistry and Chemical Technology in XXI Century (CCT 2016), $4 \mathrm{p}$

20. Kudrin V.S., Kudrina M.A., Shuryaga T.N. Redkomatalnye metasomaticheskie obrazovaniya, svyazannye s subshchelochnym

\section{Information about the authors}

Konstantin L. Novoselov, Cand. Sc., associate professor, National Research Tomsk Polytechnic University. granitoidami [Rare metals metasomatic formations related to subalkalic granitoids]. Geologiya mestorozhdeniy redkikh elementov [Geology of the rare elements deposits]. Moscow, Nedra Publ., 1965. Iss. 25, 147 p.

Received: 18 June 2019. 